\title{
The First Whole Genome Sequence and Characterisation of Avian Nephritis Virus Genotype 3
}

\author{
Paula Lagan Tregaskis*(D), Ryan Devaney and Victoria J. Smyth (D) \\ Virology, Veterinary Science Division, Agri-Food and Biosciences Institute, Stormont, \\ Belfast BT4 3SD, Northern Ireland, UK; ryan.devaney@afbini.gov.uk (R.D.); \\ victoria.smyth@afbini.gov.uk (V.J.S.) \\ * Correspondence: paula.lagan@afbini.gov.uk
}

check for updates

Citation: Lagan Tregaskis, P.; Devaney, R.; Smyth, V.J. The First Whole Genome Sequence and Characterisation of Avian Nephritis Virus Genotype 3. Viruses 2021, 13, 235. https://doi.org/10.3390/ v13020235

Academic Editor:

Stacey Schultz-Cherry

Received: 23 December 2020

Accepted: 27 January 2021

Published: 3 February 2021

Publisher's Note: MDPI stays neutral with regard to jurisdictional claims in published maps and institutional affiliations.

Copyright: (c) 2021 by the authors. Licensee MDPI, Basel, Switzerland. This article is an open access article distributed under the terms and conditions of the Creative Commons Attribution (CC BY) license (https:// creativecommons.org/licenses/by/ $4.0 /)$.
Abstract: Avian nephritis virus (ANV) is classified in the Avastroviridae family with disease associations with nephritis, uneven flock growth and runting stunting syndrome (RSS) in chicken and turkey flocks, and other avian species. The whole genome of ANV genotype 3 (ANV-3) of 6959 nucleotides including the untranslated $5^{\prime}$ and $3^{\prime}$ regions and polyadenylated tail was detected in a metagenomic virome investigation of RSS-affected chicken broiler flocks. This report characterises the ANV-3 genome, identifying partially overlapping open reading frames (ORFs), ORF1a and ORF1b, and an opposing secondary pseudoknot prior to a ribosomal frameshift stemloop structure, with a separate ORF2, whilst observing conserved astrovirus motifs. Phylogenetic analysis of the Avastroviridae whole genome and ORF2 capsid polyprotein classified the first complete whole genome of ANV-3 within Avastroviridae genogroup 2.

Keywords: avian nephritis virus; astrovirus; phylogenetics; molecular characterisation; genotyping and recombination

\section{Introduction}

Astrovirus is considered an important human and animal pathogen known to cause gastroenteritis and other systemic diseases. The RNA virus has also been associated with neurological disease in mink, ovine and bovine species, and immunocompromised humans [1-4]. The Astroviridae family is split into two genera, namely Avastrovirus (of birds) and Mamastrovirus (of mammals). Avastrovirus disease was firstly recognised in 1965 as a hepatitis disease that occurred in ducklings, later described as an astrovirus-like agent in 1984 [5,6]. The Avastrovirus genus is composed of three genogroups designated Avastrovirus group 1 to 3 with avian nephritis virus (ANV) placed in Avastrovirus genogroup 2. Infection by ANV affects birds globally with pathogenesis ranging from subclinical infection to death, depending on the age of the bird and differing field strains [5,7-14]. Typically, ANV infection causes enteric and kidney disease in chicks and young birds; symptoms may include diarrhoea, uricosis (gout), stunting, tubulonephrosis, interstitial nephritis and mortality [11,15-18].

The isolation of ANV first occurred in 1979 from a chicken faecal sample, from a flock in which the infection was subclinical but caused pathological kidney changes in chicks [7]. Although originally described as an enterovirus-like picornavirus, reclassification after molecular characterisation identified ANV as a new member of Astroviridae [19], subsequently termed ANV-1. Under a negative stain electron microscope image, the astrovirus measures $28-30 \mathrm{~nm}$ and can be seen as a five-pointed star, although this conformation is reflective of $\mathrm{pH}[20,21]$. A second ANV was identified in 1989, now known as ANV-2 as it is serologically distinct from ANV-1 [22,23].

Structurally, ANV is a small, round, non-enveloped virus containing a single-stranded positive sense RNA genome. The astrovirus genome, including that of ANV, is structured as three open reading frames (ORFs) situated between $5^{\prime}$ and $3^{\prime}$ untranslated regions (UTR) 
with a $3^{\prime}$ polyadenylated tail (poly-A tail) [24,25]. ORF1a is located after the short 5' UTR, followed by overlapping ORF1b coding for two non-structural polyproteins (nspla and nsp1b) that are subsequently cleaved by proteolytic processing into the non-structural proteins necessary for genome replication [26]. The cleaved smaller peptides of ORF1a form a viral serine protease with a nuclear localisation bipartite signal motif (NLS) whereas ORF1b, through a frameshift translational mechanism, codes for the protein RNA-dependant RNA polymerase $[24,27,28]$. ORF2 encodes the structural capsid polyprotein protein that is initially cleaved by caspases, then trypsin enzymes. The $\mathrm{N}$-terminal structural basic domain forms the capsid structure, whereas the hypervariable C-terminus contains the capsid spikes and acidic domains [26,29].

To date, three known serotypes of ANV exist, as designated from indirect immunoflorescence and virus neutralisation assays $[11,14,23,30,31]$ and are numbered ANV-1, -2 , and -3 . Originally, ANV was documented as the only known avian astrovirus to be cultivated in primary chicken kidney cell culture, whereas other astroviruses were required to be adapted and trypsin activated to cell culture from isolates of embryonated eggs $[8,28,32]$. Contrary to this, further studies have documented difficulties in virus isolation of $\mathrm{ANV}$, which in turn have prevented the necessary serological assays required for serotyping $[11,31]$. Classification has since relied on genotyping and inherent levels of ANV diversity suggest that the genotypes may be serologically distinct. The high level of diversity in positive sense RNA astroviruses occurs from the accumulation of genetic drift by point mutations and genetic shift through the mechanism of recombination, creating novel variants [33-37]. A study of ANV capsids circulating in UK poultry flocks reported that genetically diverse ANVs were found in the same flocks sampled at different times and ANV co-infections in the same flock were not uncommon [31]. Using group (genotype) clustering levels of $80 \%$ amino acid homology, eight potential groups (genotypes) have been identified [31,38] but, more recently, the eight genotypes were extended further to nine genotypes with an adapted criterion based on International Committee on Taxonomy of Viruses (ICTV) pairwise distance (p-distance) criteria [39].

Enteric disease in the poultry industry is responsible for huge economic losses worldwide, with a malabsorption disease, named runting-stunting syndrome (RSS), of partially determined aetiology, resulting in major culls of young flocks [30,40,41]. Commercial RSS-affected broiler flocks display poor feed conversion with poor growth rates, and are managed through culling of affected birds. Collectively, studies have detected numerous viruses which may contribute as co-infections to cause RSS, including ANV, chicken astrovirus (CAstV), fowl adenovirus (FAdV), chicken parvovirus (ChPV), infectious bronchitis virus (IBV), group A avian rotavirus (AvRT), and avian reovirus (ARV) [36,42-49]. Although ANV 1-3 genotypes, which appear by phylogenetic clustering based on amino acid homologies and approximate to ANV 1-3 serotypes, are detected in non-RSS-affected flocks, a recent study found that only the ANV-2 and ANV-3 genotypes were detected in samples from a small number of RSS-condemned flocks with ANV-2 viral detection at a higher abundance, indicating a possible greater pathogenetic effect [47].

Experimental infection studies of chicks concluded that age is an important factor in ANV pathogenicity, as the younger the is chick when infected, the more susceptible the chick is to developing disease [8]. A study of chicks experimentally inoculated with ANV at hatch reported clinical observations of stunting, enteric changes, diarrhoea, and discoloration of the kidneys [19]. The Narita et al. study (1990b) demonstrated similar results, although several chicks that died post-infection also had heavy urate deposits throughout their bodies, specifically on the peritoneum, liver, heart, and the leg tendons [17]. The histological findings were of renal degeneration and inflammation, lesions from the necrosis of tubular cells, and signs of pneumonitis around the parabronchi [17]. Other manifestations observed in the embryos included dwarfism, gelatinous consistency, oedema, haemorrhages, lesions, swollen kidneys, dilated ureters, urate deposits across the viscera, heart, and kidneys, and mortality [14,50-52]. 
Transmission of ANV is predominantly horizontal although it is also tentatively assumed to be vertically transmitted. For instance, a research study detected ANV in deadin-shell duck embryos in the absence of other known duck viral diseases [53]. Interestingly, an experimental challenge in embryos from parents vaccinated with the ANV-2 serotype (M-8 strain also classified as genotype ANV-2) and non-vaccinated breeding hens indicated that ANV maternal antibody protection occurred, preventing pathological damage and the replication of virus in the embryos' kidneys but not the intestines [23,50]. This experimental vaccine resulted in maternal antibody levels being elevated, allowing good ANV protection, however, the antibody protection from natural ANV infections was observed to give a lower level of protection but reduced mortality [50,54]. As alluded to by Todd et al., a vaccine would need to encompass all the antigenetically diverse ANV strains to be commercially viable [31].

This study presents the first molecular characterisation of the complete ANV-3 genome sequence isolated from an RSS-affected UK broiler flock. The genetic characterisation demonstrates a partially overlapping ORF1a and ORF1b and a non-overlapping ORF2, conserved domains, and a heptameric ribosomal frameshift (RFS) mechanism. A review of the phylogenetic classification study of the ANV capsid amino acid ORF2 region and whole genome of Avastrovirus has accentuated the difficulties in the assignment of ANV genotypes.

\section{Materials and Methods}

\subsection{Sample Preparation and Next Generation Sequencing}

The gut contents of 2 to 7 birds with RSS from each of 5 flocks of broiler chickens aged 13-31 days and from 2 normal flocks were pooled per flock and prepared, followed by viral enrichment, as described in Devaney et al. (2016) [47]. In order to provide sufficient amounts of nucleic acids for the production of next generation sequencing (NGS) libraries, nucleic acids from each pooled flock sample underwent both whole genome amplification (WGA) and whole transcriptome amplification (WTA) using REPLIg kits (Qiagen, Hilden, Germany). The amplified nucleic acids (DNA and complementary DNA (cDNA) from the 7 flock samples were used to make 7 DNA and 7 cDNA libraries. Briefly, the 14 libraries were sequenced by de novo methods on a MiSeq instrument (Illumina, San Diego, USA) using the Nextera XT library preparation kit v3 (600 cycles) (Illumina) and run as $300 \mathrm{nt}$ paired end reads as set out by the manufacturer's kit instructions. MiSeq sequencing reads were assembled in Basespace (Illumina) using the velvet assembly tool v1.0.0 [55,56]. Assembled contigs (contiguous sequences) were identified through comparison to existing sequences using the NCBI Basic Local Alignment Tool (BLAST) non-redundant database (nr) [57], visualised using Metagenome Analyser v5.7.1 (MEGAN) [58,59], and uploaded to the metagenomics analysis server MG-Rast [60] http: / / metagenomics.anl.gov / linkin.cgi?project=17287, accession number 4689855.3 (VF14-92 A2), as described by Devaney et al. (2016) [47]. The ANV genome was further analysed in Geneious v10 (Biomatters Ltd., Auckland, New Zealand) and identified gaps were filled by conventional Sanger sequencing (patch PCR). The NGS contigs and patch PCR of ANV-3 full genome sample VF 14-92-A2 presented a low depth of coverage. To confidently confirm the ANV-3 whole genome sequence (WGS), a positive ANV-3 sample with a higher abundance of reads, from a subsequent NGS study, was also characterised. The VF16-03-164b sample came from a poorly performing broiler flock (day 11 chicks), upon which WGS was performed to gain a greater genome coverage depth. The WGS results of both ANV-3 strains were submitted to NCBI with accession numbers MT585643 (VF14-92/A2) and MT585644 (VF16-03/164b).

\subsection{Sequencing, Phylogenetic, and Recombination Analysis}

The alignment for primer design was carried out in Geneious v10 (Biomatters Ltd.). Sanger sequencing was performed commercially. The assembled contigs were mapped to reference strains of ANV-1 from China (HM029238) and pigeon ANV (HQ889774) to 
create a scaffold reference mapping genome. From the results of the NGS, it was observed that an almost complete genome of ANV was present from sample VF14-92-A2, which originated from a flock with RSS. Primers were designed to patch sequence the gaps in the partial genome and to identify the sequences at the UTR $5^{\prime}$ and $3^{\prime}$ ends of the ANV genome through Sanger sequencing (Table 1). The p-distance, multiple sequence alignment (MSA), and phylogenetic trees were completed in Mega X (version 10.0.4) [61] to avail of the alignment tool, Multiple Sequence Comparison by Log-Expectation (MUSCLE) and phylogenetic tree builder through maximum likelihood (ML) with 1000 bootstrapping replicates used to generate phylogenetic trees with 145 Genbank Avastrovirus sequences aligned for the capsid and 78 sequences for WGS analysis. Phylogenetic trees were graphically viewed and edited in Interactive Tree of Life [62]. The protein motifs were assigned through Introproscan [63] and annotated in Geneious (Supplementary Figures S1-S7 and Figure 1a,b). To analyse the highly variable ANV ORF2 capsid for the detection of recombination signals, recombination detection program $4 \mathrm{v} 4.100$ (inclusive of recombination detection program (RDP) methods; RDP, GENECONV, BootScan, MaxChi, SiScan, LARD, and 3SEQ) was utilised, where accepted recombination events had $p$-values of $\leq 0.05$ from over four methods after Bonferroni correction [64-72].

Table 1. Avian nephritis virus (ANV) primer sequence specifications. Sanger sequencing primers for patch sequencing of MT585643 VF14-92-A2.

\begin{tabular}{|c|c|c|c|c|c|}
\hline $\begin{array}{l}\text { Primer } \\
\text { Name }\end{array}$ & Primer Sequence $\left(5^{\prime}-3^{\prime}\right)$ & Annealing Temp $\left({ }^{\circ} \mathrm{C}\right)$ & $\begin{array}{l}\text { Amplicon Size } \\
\text { in Base Pairs (nt) }\end{array}$ & $\begin{array}{l}\text { Position in the } \\
\text { ANV-3 VF14-92-A2 } \\
\text { Genome }\left(5^{\prime}-3^{\prime}\right) \text { (nt) }\end{array}$ & Assay \\
\hline $\begin{array}{l}1 \mathrm{AF} \\
1 \mathrm{AR}\end{array}$ & $\begin{array}{l}\text { GCGCAAAGTGACTCTAG } \\
\text { CAAGTGCCAGAGCTTC }\end{array}$ & 55 & 425 & $\begin{array}{l}341-357 \\
749-764\end{array}$ & In-house \\
\hline $\begin{array}{l}2 \mathrm{AF} \\
2 \mathrm{AR}\end{array}$ & $\begin{array}{l}\text { GCTTGGATTGACTACCAG } \\
\text { CTGAGCGCTGCTTCT }\end{array}$ & 55 & 323 & $\begin{array}{l}2363-2380 \\
2671-2685\end{array}$ & In-house \\
\hline $\begin{array}{l}3 \mathrm{AF} \\
3 \mathrm{AR}\end{array}$ & $\begin{array}{l}\text { AGGGATTGAACTTCCTG } \\
\text { TATCTGCCTAGTGAGACC }\end{array}$ & 54 & 332 & $\begin{array}{l}4527-4543 \\
4841-4858\end{array}$ & In-house \\
\hline $\begin{array}{l}4 \mathrm{AF} \\
4 \mathrm{AR}\end{array}$ & $\begin{array}{l}\text { CCTGAAGCTGTGTCCTA } \\
\text { GTCCAGAAATCGTACCAAG }\end{array}$ & 51 & 365 & $\begin{array}{l}4465-4481 \\
4811-4829\end{array}$ & In-house \\
\hline $\begin{array}{l}5 \mathrm{AF} \\
5 \mathrm{AR}\end{array}$ & $\begin{array}{l}\text { AGGTCATTTCCACCTACTC } \\
\text { TTCGAGTTGATCCACAC }\end{array}$ & 54 & 777 & $\begin{array}{l}5716-5816 \\
6558-6574\end{array}$ & In-house \\
\hline $\begin{array}{l}6 \mathrm{AF} \\
6 \mathrm{AR}\end{array}$ & $\begin{array}{c}\text { GCCCGGAGAAGGCGACT } \\
\text { TCGAGTTGATCCACACAATCAAACCTC }\end{array}$ & 53 & 345 & $\begin{array}{l}6229-6245 \\
6547-6573\end{array}$ & In-house \\
\hline $\begin{array}{l}5^{\prime} \mathrm{F} \\
5^{\prime} \mathrm{R}\end{array}$ & $\begin{array}{l}\text { CCGAATAGATGGGATGGCT } \\
\text { GTCATCACAGCCTTTTCCTC }\end{array}$ & 50 & 321 & $\begin{array}{c}1-19 \\
302-321\end{array}$ & In-house \\
\hline $\begin{array}{l}3^{\prime} \mathrm{F} \\
3^{\prime} \mathrm{R}\end{array}$ & $\begin{array}{l}\text { GTAAACCACTGGYTGGCTGACT } \\
\text { TTTTTTTTTTTTAAAAGTTAGC }\end{array}$ & 50 & 271 & $\begin{array}{l}6682-6703 \\
6931-6952 \\
\end{array}$ & $\begin{array}{c}{[73]} \\
\text { In-house }\end{array}$ \\
\hline $\begin{array}{l}\text { Pre-ORF2 } \\
\text { Post-ORF2 }\end{array}$ & $\begin{array}{c}\text { ACCTTGAATCCCTGTGGGGCA } \\
\text { AAAAGTTAGCCAATTCAAAATTAATTC }\end{array}$ & 57 & 2535 & $\begin{array}{l}4406-4426 \\
6914-6940\end{array}$ & [31] \\
\hline
\end{tabular}

\subsection{ANV-3 Sequence Confirmation}

To confirm the ANV-3 genome width coverage, whilst achieving an appropriate read depth coverage, a sample with a higher read abundance of ANV-3 determined by DIAMOND [74] and MEGAN analysis was selected. Initially, this sample, VF16-03-164b, was processed by Trim Galore [75] to a $Q \geq 30$ score with validated reads viewed on MultiQc [76]. To map the validated VF16-03-164b reads, the read aligner program BWAMEM [77] with VF14-92-A2 as the reference sequence was utilised through Galaxy GVL [78] via CLIMB [79]. The Tablet program [80] enabled the visualisation of the ANV-3 reference sequence VF14-92-A2 and aligned it to VF16-03-164b for genome coverage and read depth. As a secondary confirmation of depth and genome width coverage, the reads of VF16-03164b were also mapped to VF14-92-A2 ANV-3 WGS in Geneious by 5 iterations in high sensitivity mode (Figure 4a,b). 


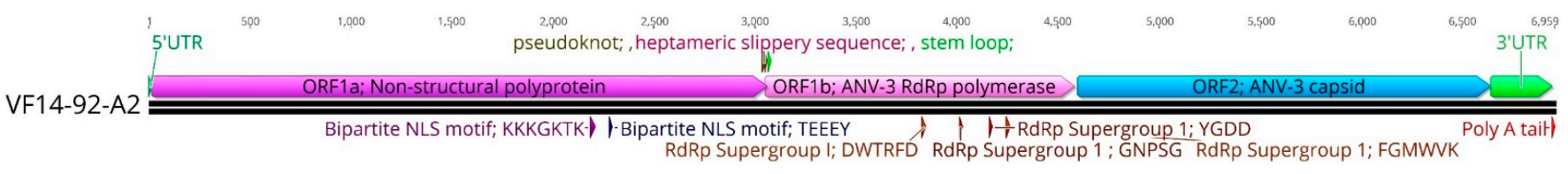

(a)

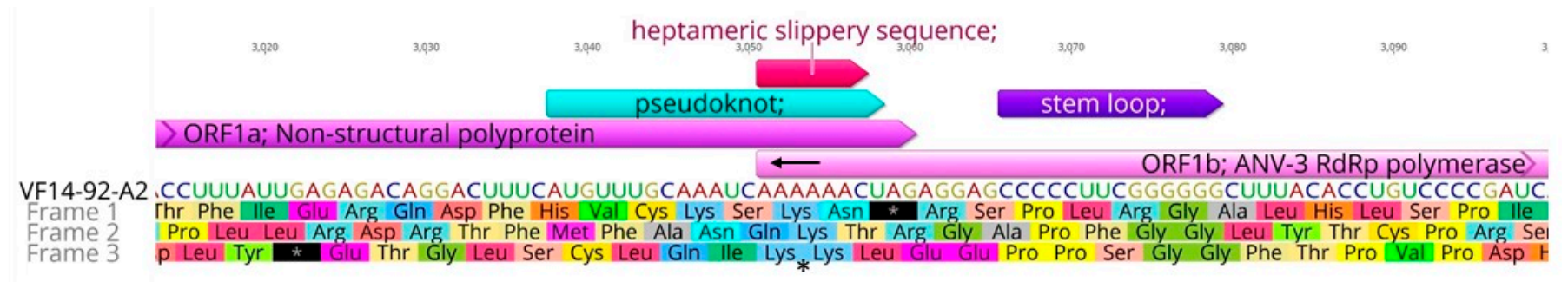

(b)

Figure 1. Schematic representation of ANV genotype 3 whole genome and ribosomal shift mechanism. (a) Schematic representation of ANV genotype 3 whole genome structural organisation comprising a partially overlapping open reading frame 1a (ORF1(a) and ORF1b and separate ORF2. Motifs and secondary structures located in ORF1a nuclear localisation signal NLS) bipartite KKKGKTK and TEEEY, ORF1b RdRp motifs DWTRFD, GNPSG, YGDD, and FGMWVK. (b) Schematic representation of the partially overlapping and -1 (signified by an arrow) ORF1a and 1b ribosomal frameshift signal with mapped pseudoknot, heptameric slippery sequence, and stemloop. The lysine amino acid (K) in frame 3 where translation recommences after the ribosomal frameshifting signal (RFS) is marked as *.

\section{Results}

The ANV-3 VF14-92-A2 strain genome, at 6959 nt in length, is characterised by an overlapping genetic region of ORF1a (3045 nt) and ORF1b (1530 nt) wherein lies the conserved ribosomal frameshifting mechanism, with ORF2 (2040 nt) reading in the same frame as ORF1a, and all of which are positioned within a short 5' UTR and a longer 3' UTR (319 nt) inclusive of the 3'poly-A tail (Figure 1a). The ORF1a polyprotein $\mathrm{M}_{\mathrm{r}}$ is calculated at 113.451 kilo Daltons (kDa), ORF1b polyprotein is $59.084 \mathrm{kDa}$, and ORF2 polyprotein is $73.872 \mathrm{kDa}$. The 5' UTR is $15 \mathrm{nt}$ long and begins with a characteristic sequence conserved across Avastrovirus species, CCGAA, followed by ORF1a reading in frame 1, starting at position $16 \mathrm{nt}$ to $3060 \mathrm{nt}$ encoding a polyprotein of 1014 amino acids (aa). A conserved peptidase domain, the homologous Superfamily 1 trypsin 2-like peptidase domain, was identified mid-ORF1a from 517 to 642aa (pfam13365).

A conserved bipartite nuclear localisation signal (NLS) motif comprising KKKGKTK and TEEEY motifs (761 to 765aa) is also present in ORF 1a (Figure 1a). The conserved replication feature of astrovirus is a frameshift structure mechanism where an overlapping ORF1a and ORF1b region occurs due to a shared heptameric sequence known as a "slippery sequence" which creates a -1 ribosomal frameshift signal (RFS) (Figure 1b) where the ribosome shifts, in the $5^{\prime}$ direction, by one nucleotide [81]. This frameshift translation mechanism requires two cis-acting sequence elements, the heptameric slippery sequence and the stemloop secondary structure [27,82]. In strain VF14-92-A2, the ORF1a stop codon is located at nt positions 3058-3060 immediately downstream of the ORF1b partial overlapping polyprotein heptameric slippery sequence which begins at nt position 3051, ending at 3057 (AAAAAAC), which is followed by a stemloop structure sequence between position 3066-3079 nt (the underlined nucleotides form the base-pairing structure of the stemloop: CCCCCUUCGGGGGGC).

The translation continues after the -1 base ribosomal frameshift, from frame 1 , to continuing translation from the lysine aa by shifting to reading in frame 3 (Figure 1b). Notably, no AUG start codon (methionine) exists immediately preceding the heptameric slippery sequence in ANV, as seen in chicken astrovirus, however, a start codon is present in both ANV and chicken astrovirus located from 12-17 nt upstream of the slippery sequence, 
although is only translatable into methionine in ANV in frame 2, which is non-viable due to the presence of multiple stop codons downstream (Figure 1b). A start codon is also found before the stemloop in chicken astrovirus and duck astrovirus, although this is intermittent in ANV, and whilst present in strain VF16-03-164b, it is absent from VF14-92-A2 (Figure 2). The goose astrovirus genotypes differed in comparison to the other Avastrovirus species, with no start codons before the heptameric slippery sequence or stemloop regions.

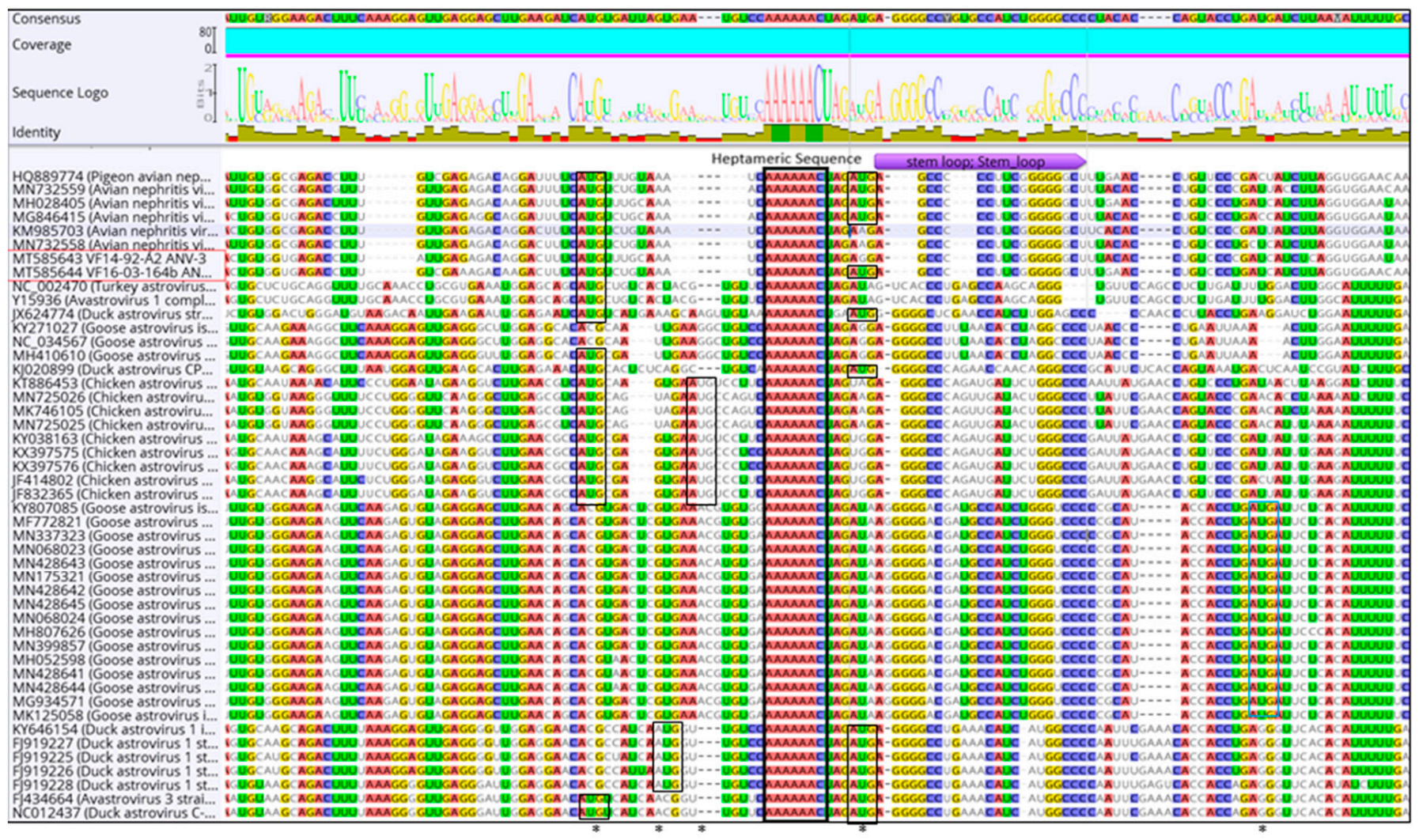

Figure 2. Astroviridae ribosomal frameshift mechanism ORF1a and ORF1b. Alignment of the Avastroviridae whole genome heptameric slippery sequence and stemloop region including ANV-3 strains and MT585643 VF14-92-A2 and MT585644 VF16-03-164b. Red box is ANV VF14-92-A2 and VF16-03-64b, blue box and *identify the methionine/putative start codons, and the black box marks the heptameric slippery sequence.

The VF14-92-A2 stemloop motif was confirmed in the RNAfold program with minimum free energy (MFE) modelling (http:/ / rna.tbi.univie.ac.at) (Figure 3a) with a pseudoknot observed prior to the slippery sequence, creating a more complex configuration to increase the efficiency of the RFS by slowing or stalling the ribosome and was confirmed in the ANV-3 VF16-03-164b sequence (Figure 3b).

The VF 14-92-A2 isolate possesses a short overlap of only $10 \mathrm{nt}$, in which the heptameric RFS is located, at the $3^{\prime}$ end of ORF1a and 5' end of ORF $1 b$, shifting the reading frame of ORF $1 \mathrm{~b}$, which codes for the polyprotein RNA-dependant RNA polymerase $(R d R p)$ of 509aa (Figure 1a,b). As seen in other astroviruses, the RdRp centre forms the conserved Supergroup 1 motifs $[19,27,83]$. The RdRp is translated -1 in frame 3 and ANV-3 RdRp motifs were mapped at DWTRFD (3828 to $3845 \mathrm{nt}$ ), GNPSG (4011 to $4025 \mathrm{nt}$ ), YGDD (4161 to $4172 \mathrm{nt}$ ), and FGMWVK (4245 to $4262 \mathrm{nt}$ ) and confirmed by Interpro PFam analysis (Clan RdRp CL0027 and CD cd01699 RNA dep RNAP) (Supplementary Figures S2 and S6). The conserved avastrovirus spacer gap (Figure 1a), although not present in passerine Avastrovirus, is a short $19 \mathrm{nt}$ stretch between ORF1b and the ANV-3 capsid ORF2 and is present in both ANV strains. It facilitates a second frameshift, allowing ORF 2, which codes for a 680aa polyprotein, to switch to frame 1 during translation (4600 to $6639 \mathrm{nt}$ ), whereas, in other mammalian and reptile astroviruses, ORF1b and ORF2 overlap [84,85]. 
The relatively long 3' UTR of $303 \mathrm{nt}$, excluding the polyadenylated tail, with a complex stemloop II motif, when analysed by RFam, matches a similar coronavirus 3' stemloop II-like motif ( $\mathrm{s} 2 \mathrm{~m})$, as seen in other astrovirus species and ANV strains, although not detected in turkey astrovirus genogroup 2 [86]. The $\mathrm{s} 2 \mathrm{~m}$ is located from 78 to $120 \mathrm{nt}$ in the UTR (nt position 6716 to 6756 ) and the RNA secondary structure was confirmed through MFE modelling (Supplementary Figure S8) [87].

(a). VF14-92-A2 ANV-3

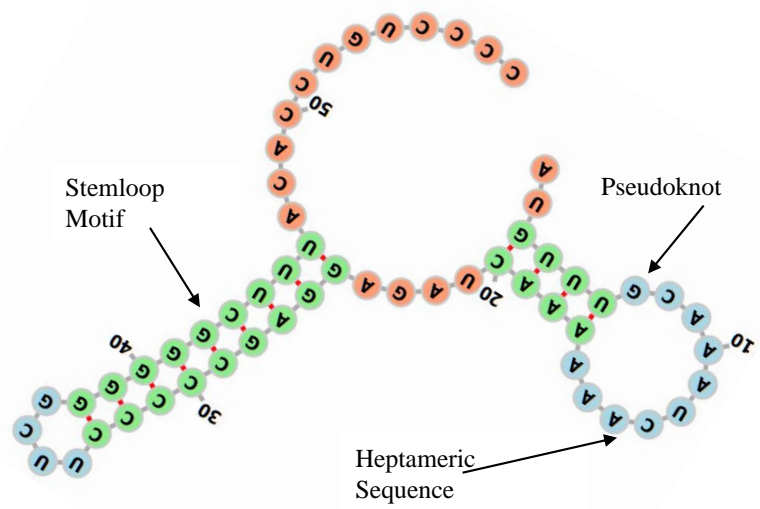

(b). VF16-03-164b ANV-3

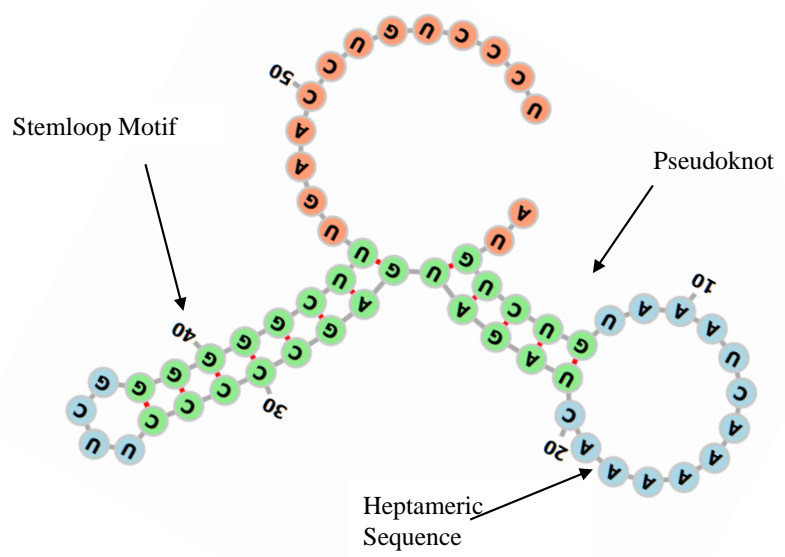

Figure 3. (a,b) RNAfold secondary structures of pseudoknot, heptameric slippery sequence, and stemloop with a minimum free energy (MFE) of -16.8 kcal/mol for MT585643 VF14-92-A2 and 164b -17 kcal/mol MFE for MT585644 VF16-03-164b.

\subsection{Confirmatory NGS Genome Coverage}

The VF14-92-A2 WGS, as a reference strain, mapped reads from a confirmatory sample (VF16-03-164b) to yield full genome width and depth coverage, although, as anticipated, the coverage was uneven and the $5^{\prime}$ and $3^{\prime}$ UTRs returned low coverage (Figure $\left.4 a, b\right)$. The Geneious reference mapping algorithm, from 5 iterations, mapped 9241 reads. The ORF1a 3 ' region had the highest coverage at a 1042 read depth. The BWA-MEM algorithm and Tablet visualisation showed a similar profile to confirm the presence of the ANV-3 genome.

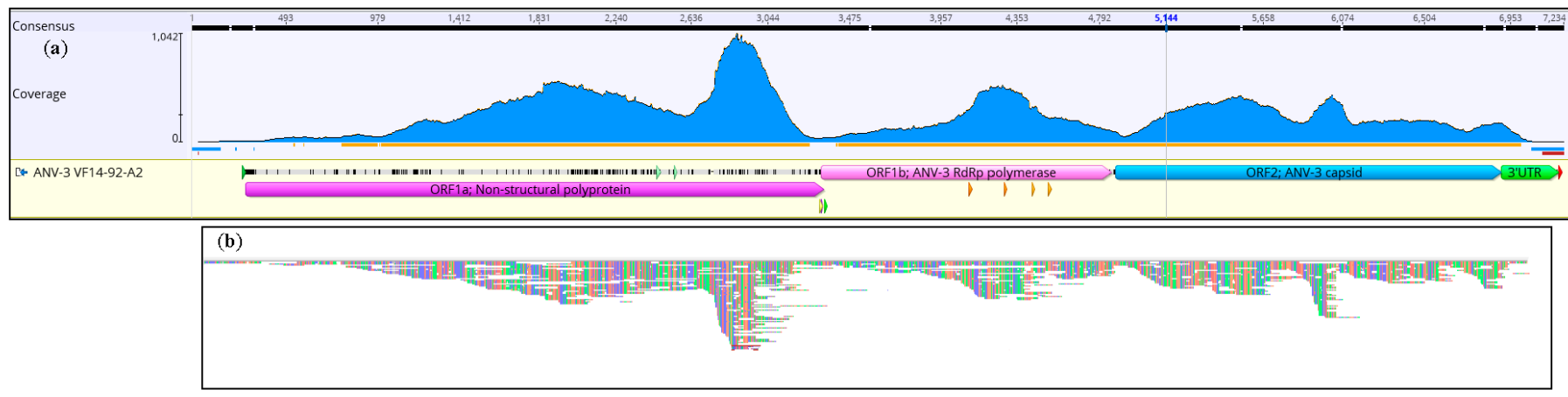

Figure 4. Genome coverage of ANV-3. (a) The whole genome coverage validation of ANV-3 reads from MT585643 VF14-92A2 with MT585644 VF16-03-164b used as a reference sequence. The Geneious read mapping algorithm, set at 5 iterations, resulted in whole genome coverage with 9241 reads. The ORF1a 3' region had the highest coverage at a 1042 read depth. (b) The BWA-MEM read aligner/Tablet visualisation showed a similar profile to Geneious and whole genome breadth and depth of coverage. 


\subsection{Amino Acid Percentage Homology, Pairwise Distance Percentage Homology, and Recombination}

The complete VF14-92-A2 ANV-3 capsid polyprotein 680 aa sequence aligned with other Avastrovirus sequences deposited in Genbank (NCBI) and designated the VF14-92-A2 and VF16-03-164b strains in the same clade with 92.4\% aa homology and as an ANV-3 genotype (Figure 6). The comparison of ANV-3 VF14-92-A2 as an intra-genotype aa percentage identity resulted in a homology similarity of $83.3 \%$ to KM985691 and 94.9\% to HQ330481. Within the capsid polyprotein alignment, the most divergent ANV isolate to VF14-92-A2 found ANV genotype 6 KU711057 Brazil 19-5 at a low 54.6\% nucleotide homology.

The Avastrovirus genogroup classification by $\mathrm{p}$-distance criteria is currently under review by the ICTV, however, it sets the demarcation criteria of the p-distance limit between genogroups as $0.704+0.013 \mathrm{https}$ / / talk.ictvonline.org [84]. Currently, the ICTV classifies all ANV strains by aa p-distance of the capsid Avastrovirus as intra-genogroup 2, including the sequences from this study, ranging from 0 to 0.588 and with an inter-genogroup $\mathrm{p}$ distance range of $>0.7290$ to 1.45 (Supplementary Table S1). The aa p-distance of VF14-92-A2 ANV-3 to the most divergent isolate of Avastrovirus genogroup 2 ANV was the Brazilian strain, ANV genotype 6, KU711057, at 0.551. Within the ICTV Avastrovirus genogroup 2, the closest homology to ANV-3 VF14-92-A2 was from ANV UK strains HQ330481 and HQ330494, with a p-distance of 0.041 (Figures 5 and 6 and Supplementary Table S1). The Avastrovirus whole genome nucleotide MSA p-distance was calculated to reveal that within the ANV genogroup, the p-distance ranged from 0 to 0.309 , and between other Avastrovirus inter-group clades from 0.340 to 1.019 (Supplementary Table S2).

The genetic recombination analysis of ANV capsid strains revealed putative recombination signals as common events, with some strains even possessing multiple recombination events. Specifically, the RDP4 program found that the ANV-3 strains VF14-92-A2 and VF16-02-163b both had a putative recombination signal at the C-terminus region of ORF2 (Table S3 and Figure S9a,b). An acceptable p-value of less than 0.05 was generated from RDP4 programs RDP, GENECONV, BootScan, MaxChi, SiScan, Phylpro, LARD, and 3Seq, with VF14-92-A2 $p$-values of $9.58 \times 10^{-3} 9.005 \times 10^{-1}, 3.854 \times 10^{-2}, 2.053 \times 10^{-5}$, $1.001 \times 10^{-16}, 3.275 \times 10^{-4}, 1.327 \times 10^{-6}$, and $3.275 \times 10^{-4}$, and VF16-03-164b p-values of $1.031 \times 10^{-10}, 1.830 \times 10^{-5}, 1.881 \times 10^{-9}, 1.558 \times 10^{-10}, 5.135 \times 10^{-19}, 3.885 \times 10^{-20}$, $5.810 \times 10^{-31}$, and $3.885 \times 10^{-20}$, respectively. The breakpoints in each strain were both similar, with the VF14-92-A2 nucleotide position region occurring at 1374-2258 and for VF16-03-164b at positions 1298-2252, however, the identified major and minor parental donors were from different intergenic clades. The VF14-92-A2 potential major parent was KU711052, an ANV-8 strain, and the potential minor parent KM985698 VIC-3c, an ANV-1 strain. However, the VF16-02-164b inferred unknown potential parent was HO086767, an ANV-1 strain, and the minor parent was KM985694 NSW-4a, also an ANV-1 strain. The parental donors speculated in this study were the most closely related recombinant donors available from the multiple sequence alignment. Further genomic screening and sequencing of circulating ANV strains may help to provide epidemiological relevance to the recombination signals found in this study. 


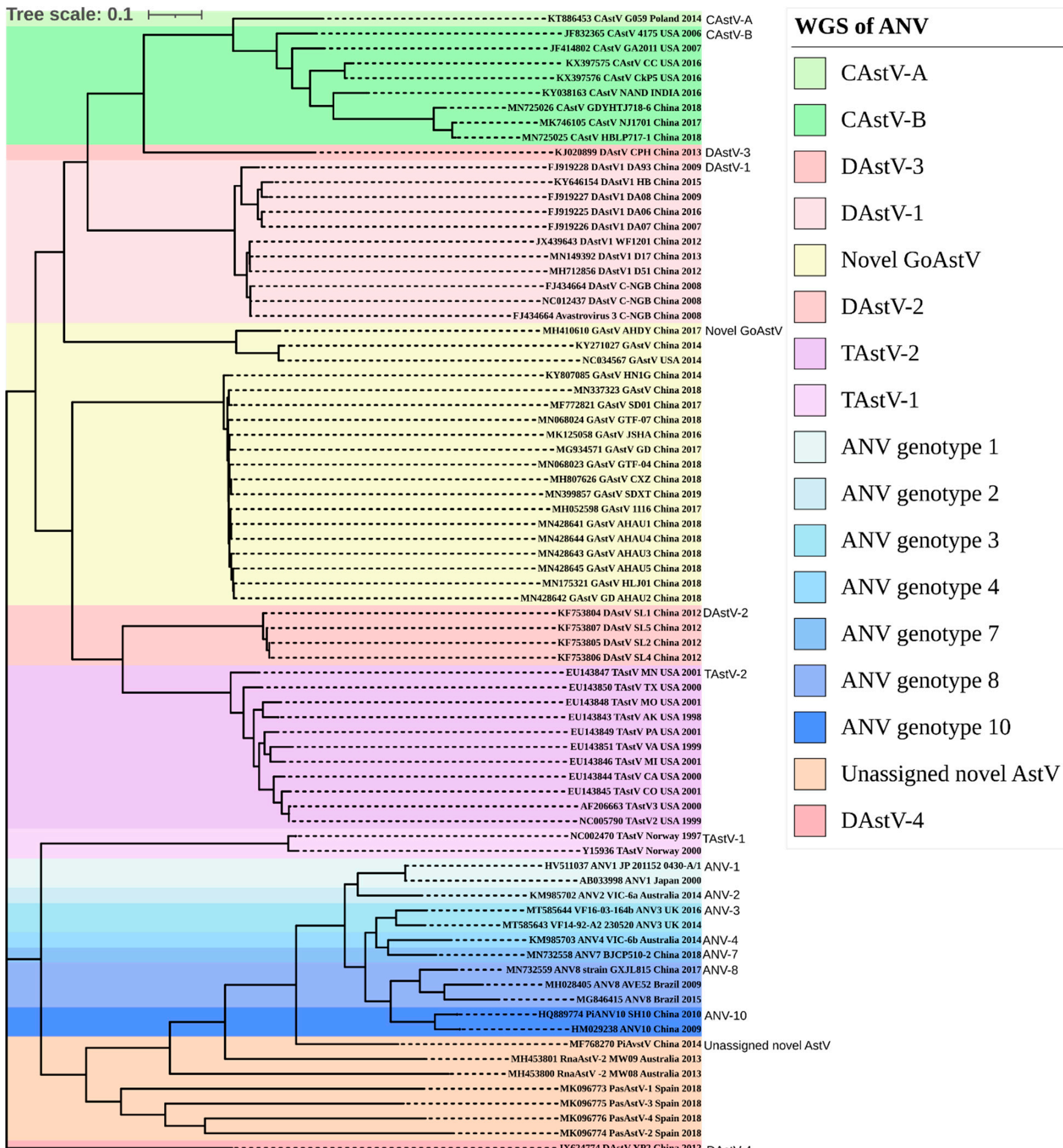

Figure 5. Astroviridae whole genome sequence (WGS) phylogeny. The Avastroviridae whole genome nucleotides of 78 sequences, starting from ORF1a phylogenetic analysis in MEGA X from MUSCLE-aligned sequences. Evolutionary history was inferred by maximum likelihood with bootstrapping of 1000 replicates. The tree was annotated into clades and ANV genotypes coloured blue with sequences from this study, with MT585643, VF14-92-A2, and MT585644 VF16-03-164b positioned in Avastrovirus genotype 3. Clade abbreviations; CAstV $=$ Chicken astrovirus, DAstV $=$ Duck astrovirus, $\mathrm{GAst} \mathrm{V}=$ Goose astrovirus, $\mathrm{ANV}=$ Avian nephritis virus, and $\mathrm{TAstV}=$ turkey astrovirus . 


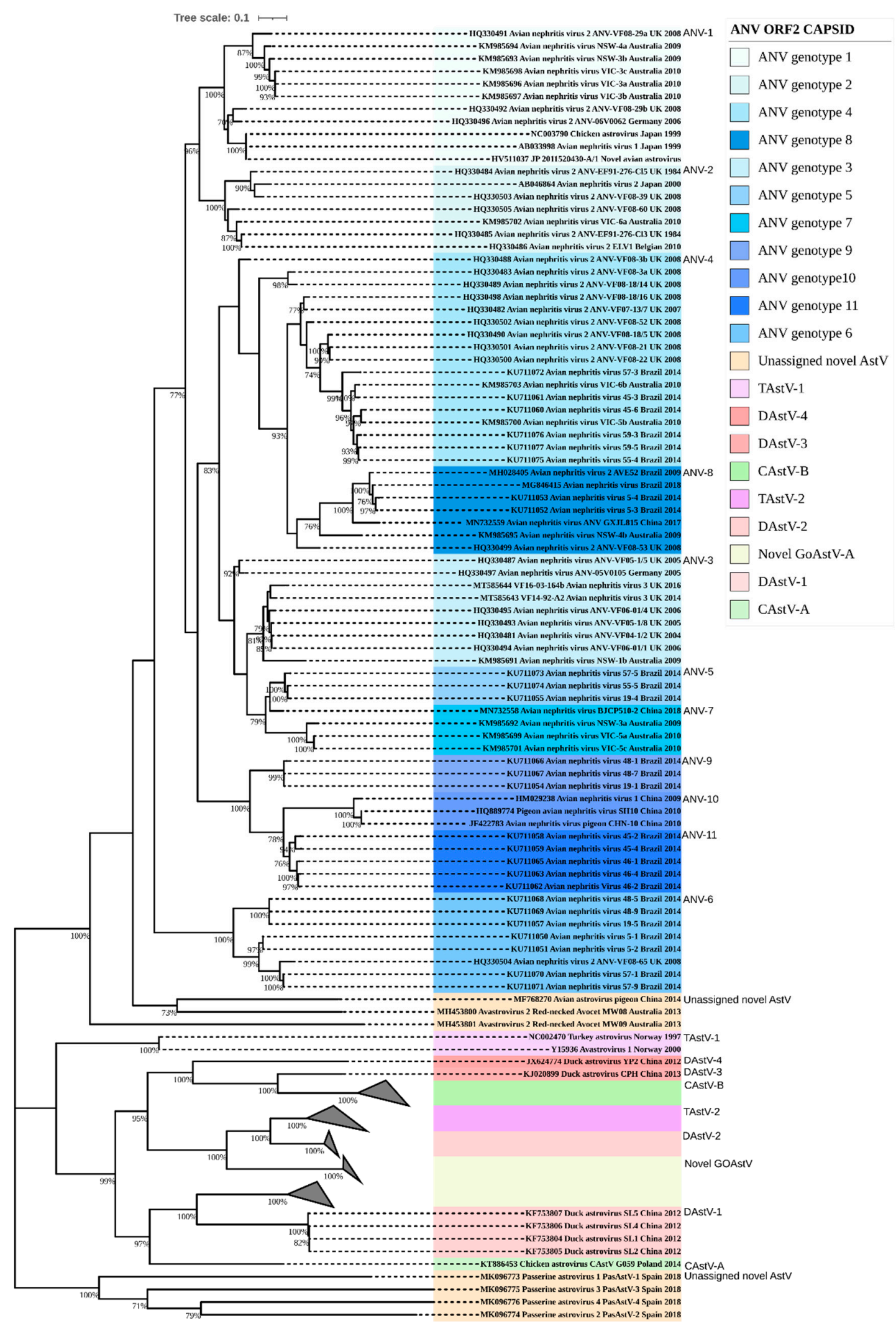

Figure 6. Astroviridae capsid ORF2 phylogeny. The Avastroviridae capsid ORF2 amino acids of 145 sequences phylogenetic analysis in MEGA X from MUSCLE-aligned sequences. Evolutionary history was inferred by maximum likelihood with bootstrapping of 1000 replicates. The tree is annotated in clades and ANV genotypes coloured blue with sequences from this study (in bold), with MT585643, VF14-92-A2, and MT585644 VF16-03-164b positioned in avian nephritis genotype 3. Clade abbreviations; $\mathrm{CAstV}=$ Chicken astrovirus, $\mathrm{DAstV}=$ Duck astrovirus, GAstV = Goose astrovirus, $\mathrm{ANV}=\mathrm{Avian}$ nephritis virus, and TAst $\mathrm{V}=$ turkey astrovirus. 


\section{Discussion}

The ANV-3 whole genome sequence characterisation is the first report of the ANV genotype 3 virus discovered, through a dual approach of NGS and Sanger sequencing methods, from an RSS-affected flock. This study sought to characterise the ANV-3 isolate VF14-92-A2 full length genomic sequence which encompasses $6959 \mathrm{nt}$, inclusive of the polyA tail (MT585643), with an additional confirmatory whole genome sequence discovered in samples from a poorly performing broiler flock VF16-03-164b (MT585644).

The genomic organisation of ANV-3 VF14-92-A2 is typical of other ANVs, commencing with a short $5^{\prime}$ UTR of $15 \mathrm{nt}$ and ending with a much longer 3' UTR of $319 \mathrm{nt}$, which is also a typical feature of Avastrovirus, although shorter than the typically longer UTR regions in the Mamastrovirus genus [86], and followed by a polyadenylated tail. Between these extremities are situated three ORFs, the first and third of which, ORF 1a and ORF 2 , are in the same frame, while the intervening ORF, ORF $1 b$, is in a different frame, which is facilitated by the overlapping region of $10 \mathrm{nt}$ at the $3^{\prime}$ end of ORF $1 \mathrm{a}$ and the $5^{\prime}$ start of ORF $1 \mathrm{~b}$, that contains the conserved heptameric slippery sequence necessary for translational frameshifts (Figure 2) and is present in all ANVs. Between ORF $1 \mathrm{~b}$ and ORF 2, there is the conserved, amongst most avastrovirus species, short $19 \mathrm{nt}$ spacer region (Figure $1 \mathrm{a}, \mathrm{b}$ ), which affects a frameshift when the positive sense single-stranded RNA genome is translated directly as messenger $(\mathrm{m}) \mathrm{RNA}$. During infection, the replication polyproteins from these three ORFs are proteolytically cleaved to form the RdRp, a protease, and capsid proteins $[25,86]$.

The NLS bipartite region identified in ANV-3 VF14-92-A2 within ORF1a aa consists of conserved motifs KKKGKTK and TEEEY (Figure 1a and Supplementary Figures S1 and S5), with similar NLS representations in other ANV-1 and ANV-3 strains and in chicken astrovirus sequences. However, historically, the bipartite motifs were proposed to have a spacer gap of only around 10 aa, whereas those of the ANV and CAstV are separated by a 23-24 aa gap [85,87-89]. A second conserved region of ORF1a is similar to a region within the serine endopeptidase S32 of equine arteritis virus, of the order Nidovirales, with serine peptidase DNA-binding activity and formation of protein dimers (Figure 1a and Supplementary Figures S1 and S5) [90].

An RFS mechanism occurs to genetically express different proteins coded by overlapping ORF mRNA during translation by changing the reading frame, shifting by one base in the $5^{\prime}(-1)$ or $3^{\prime}(+1)$ direction [91]. The RFS is observed as the translational shift "slippery site" with a short spacer sequence and a downstream secondary structure, usually either a stemloop or pseudoknot. The astrovirus ORF1a 3' end position is a partially overlapping ORF1a/1b junction with a conserved "slippery heptameric" sequence, 5'-AAAAAAC-3', and upstream of a stemloop motif to create the RFS (Figures 1b, 2 and 3). The overlapping frameshift is well documented in astrovirus, however, this analysis of the ANV-3 strains found a potential pseudoknot prior to the slippery sequence and stemloop of ORF1b, which creates a more stable and efficient RFS translating from the overlap of the reading frames at the AAA codon, lysine, by switching -1 base/frame coding the polyprotein RdRp (Figures 1b, 2 and 3). The AUG codon at the start of ORF1b, prior to the slippery sequence, is typically observed in mammalian astroviruses and CAstV; however, it is not always conserved in Avastrovirus, and is absent from all ANV genotypes, although an AUG codon is situated incidentally $12 \mathrm{nt}$ upstream of the slippery heptameric sequence in both ANV and CAstV, and earlier than the beginning of the ORF1b lysine translation, which may provide a methionine towards the C-terminal end of the ORF1a polyprotein. Furthermore, preceding the stemloop sequence, a putative methionine is found intermittently in ANV strains, where the ANV-3 VF14-92-A2 genotype strain has an aa deletion gap, and a methionine is present in the VF16-03-164b strain and all the DAstV strains, whilst, in contrast, the GAstV methionine is situated after the stemloop (Figure 2). The significance of these methionine sites as putative ribosomal initiators in the RFS mechanism remains to be determined. 
The RdRp is conserved in all RNA viruses without a DNA stage in replication in order to synthesise a complementary RNA strand from the RNA template $[19,27]$. The RdRp enzyme catalyses the replication of the RNA template to RNA and has an active catalytic centre formed of conserved motifs known as Koonin's Supergroup I DWTRFD, GNPSG, YGDD, and FGMWVK (Figure 1a and Supplementary Figures S2 and S5) [19,27,83], which are present in both of the ANV strains described herein. The astrovirus capsid gene, ORF2, normally overlaps with ORF1b, however, the ANV-3 strains and the majority of Avastrovirus strains possess a spacer gap whilst switching frames. In the ANV strains VF14-92-A2 and VF16-03-164b from this study, the spacer gap was between 13 to $19 \mathrm{bp}$.

The highly conserved 3' UTR s2m motif is observed in positive sense RNA viruses with poly-A tails, such as the Caliciviridae, Coronaviridae, Picornaviridae, and Astroviridae [85,92,93]. The s2m may be transferred to different RNA families through non-homologous recombination events and, as RNA viruses have a high mutation rate, its conservation implies the $\mathrm{s} 2 \mathrm{~m}$ has an important function [93]. Comparison of the $\mathrm{s} 2 \mathrm{~m}$ structure to the microRNAs involved in RNAi-associated gene regulation hypothesises that the s $2 \mathrm{~m}$ function may be implicated in gene silencing $[94,95]$. The 3' UTR was previously reported to contain a complex $\mathrm{s} 2 \mathrm{~m}$ in astroviruses and is similar to the coronavirus $3^{\prime} \mathrm{s} 2 \mathrm{~m}$ structure [92] and this is also confirmed for the ANV-3 VF14-92-A2 and VF16-03-164b strains (Supplementary Figure S8).

The genomic region with the highest variability is the ANV capsid gene (ORF 2) sequence where homology classification of the ANV was incepted in 2010 to genetically group ANV-1 to -6 [96]. The ANV genotypes are categorised by the application of the capsid protein with $>80 \%$ amino acid similarity as the cut-off per group. A later study extended this system to include genotypes 7 and 8 [38]. This estimate was based on the observed levels of similarity that existed between small numbers of representative strains in each of five of the proposed genogroups compared to a lower level of ORF2 amino acid homology of $71 \%$ shared between the ANV-1 and ANV-2 genotypes, which had been previously determined as serologically distinct $[8,19,97]$. As proposed by Todd, no correlation can be made when comparing ANV genotypes and the geographical location of the ANV host [31]. The Todd classification of $>80 \%$ amino acid pairwise homology definition of a genotype (group) is problematic when considering the diverse Brazilian ANV strains [39], as many of these strains intra-genotype, such as KU711057, but present a low 71\% homology within the ANV genotype 6 clade (Figures 5 and 6). Given that 71\% is also the amount of ORF2 shared amino acid homology between the two serologically distinct strains, ANV-1 and ANV-2, it may be that, in the future, the more variable C-terminal half of ORF2, which largely determines ANV antigenicity, assumes greater responsibility for ANV strain classification as opposed to the entire ORF2.

The genetic diversity of RNA viruses is fundamentally driven by the error-prone RdRp point mutations at high error rates and also recombination events [98,99]. In this study, it was observed that the ANV capsids contained frequent putative recombination signals, where multiple ORF2 recombination events may have occurred within a single ANV strain. Both VF14-92-A2 and VF16-03-164b strains' recombination signals displayed similar breakpoints in the C-terminus spike region which had previously been identified as a recombination hotspot [31]. Furthermore, the two ANV-3 strains' potential parents were putative intergenic recombination events: VF14-92-A2 ANV-3 major parent ANV-8, and minor parent ANV-1, whilst VF16-03-164b intergenically recombined with ANV-1, suggesting that ANV-3 had possibly evolved from ANV-1. The antigenic shift, due to intergenic recombination within the capsid gene, and specifically within the spike coding region, may have increased the viral pathogenicity and viral antigenic variability, leading to further difficulties in phylogenetically mapping highly divergent ANV strains.

Currently, the ICTV propose that speciation criteria of the Avastrovirus family are based on the capsid polyprotein aa mean p-distance between genogroups of $0.704+$, https://talk. ictvonline.org [84]. The p-distance of the ANV-3 VF14-92-A2 capsid aa sequence falls within the Avastrovirus genogroup 2, which encompasses all ANV genotypes, although the classification of genotypes has not been specifically defined (Supplementary Tables S1 and S2). 
The challenging endeavours to classify the highly recombinant and divergent astroviruses, combined with an expanding array of newly discovered novel sequences, has generated various classification interpretations. Previously, classification of genotypes by the $\mathrm{p}$ distance of ANV in ICTV Avastrovirus genogroup 2 was overly stringent, with the criteria set at the genotype range for highly divergent RNA viruses (p-distance up to 0.284 ) which was too narrow. However, a recent study reclassified the ANVs into genotypes based on ICTV criteria in which they altered the p-distance genogroup range of 0.414 to 0.748 and expanded within the genotype to 0.047-0.299 [39]. This study found 11 ANV genotypes, as set out in distinct clades (Figures 5 and 6 ), although the p-distance criteria by ICTV or Espinoza et al. did not succeed in separating out genotypes based on the ANVs' ORF2 amino acid sequences [39,84]. Based on the Avastrovirus ANV capsid aa, applying the intergenotype criteria created the occurrence of p-distance conflicts, for instance, HQ330486 ANV-2 placed in genotype 2 by the p-distance conflicts with a genotype 1, HQ330496, causing a low inter-genotype p-distance of 0.1894 , with similar occurrences seen across most ANV genotypes (Supplementary Table S1). The Avastroviridae WGS analysis of the nt (but not aa due to translation occurring over differing frames) p-distance was unsuccessful in providing any resolution and designating appropriate genotype criteria (Figure 5 and Supplementary Table S2).

The classification of the highly divergent ANV genotypes is challenging when adopting Todd's, ICTV's, or Espinoza's classification suggestions, as inherent complications occur. Ideally, genetic phylogeny should reflect serological diversity in order to provide useful insight into pathogenicity and immunological protection. This study, by means to classify the ANV genotypes, has separated the ANV genotypes by the interpretations of distinct clades. The whole genome sequencing of an ANV-3 strain from RSS-affected broiler chickens has permitted the genetic characterisation of the virus and genome organisational structure by establishing the conserved domains found in Avastrovirus within this strain. Along with the other full length ANV strains, genetic characterisation will enhance taxonomic classification, aid molecular assays for diagnostic detection to be developed, and enhance further understanding of the epidemiology and pathogenicity of ANV.

Supplementary Materials: The following are available online at https:/ /www.mdpi.com/1999-4 915/13/2/235/s1, Figure S1: Figure S1. Introproscan VF14-92-A2 ANV ORF1a, Figure S2. Introproscan VF14-92-A2 ANV ORF1b, Figure S3. Introproscan VF14-92-A2 ANV ORF2, Figure S4. NCBI Conserved Domains VF14-92-A2, Figure S5. Introproscan VF16-03-164b ANV-3 ORF1a, Figure S6. Introproscan VF16-03-164b ANV-3 ORF1b, Figure S7. Introproscan VF16-03-164b ANV-3 ORF2, Figure S8. VF14-92-A2 ANV-3 3'UTR s2m RNA Secondary structure, Figure S9a,b Recombination Detection Program. Table S1. Avastroviridae ORF2 Capsid p-distance, Table S2. Avastroviridae WGS p-distance, Table S3. Recombination Detection Program 4 p-values.

Author Contributions: Conceptualisation, V.J.S., R.D., and P.L.T.; Methodology, R.D. and P.L.T.; Software, P.L.T;; Validation, P.L.T.; Formal analysis, P.L.T. and V.J.S.; Investigation, P.L.T.; Resources, P.L.T., R.D., and V.J.S.; Data curation, P.LT.; Writing—original draft preparation, P.L.T.; Writingreview and editing, P.L.T. and V.J.S.; Visualisation, P.L.T.; Supervision, V.J.S.; Project administration, V.J.S.; Funding acquisition, V.J.S. All authors have read and agreed to the published version of the manuscript.

Funding: This research was partially funded by the Department of Agriculture, Environment \& Rural Affairs-Code PG 13/02, and the Agri-Food and Biosciences Institute (AFBI)—Code 44955.

Institutional Review Board Statement: Not applicable as this study included the sampling of animals for diagnostic purposes and therefore did not require approval from the ethics committee.

Data Availability Statement: The datasets generated for VF14-92/A2 are available at MG-Rast http: / / metagenomics.anl.gov / linkin.cgi? project=17287, accession number 4689855.3 and NCBI Genbank with accession numbers MT585643 (VF14-92/A2) and MT585644 (VF16-03/164b).

Acknowledgments: Victoria J. Smyth would like to acknowledge the Department of Agriculture, Environment \& Rural Affairs and AFBI in supporting this study. The authors would like 
to thank Greg Koulianos for providing samples, who at the time, was working for St. David's Poultry Team, Dungannon.

Conflicts of Interest: The authors declare no conflict of interest. The funders had no role in the design of the study; in the collection, analyses, or interpretation of data; in the writing of the manuscript, or in the decision to publish the results.

\section{References}

1. Blomstrom, A.L.; Widen, F.; Hammer, A.S.; Belak, S.; Berg, M. Detection of a novel astrovirus in brain tissue of mink suffering from shaking mink syndrome by use of viral metagenomics. J. Clin. Microbiol. 2010, 48, 4392-4396. [CrossRef]

2. Burbelo, P.D.; Dubovi, E.J.; Simmonds, P.; Medina, J.L.; Henriquez, J.A.; Mishra, N.; Wagner, J.; Tokarz, R.; Cullen, J.M.; Iadarola, M.J.; et al. Serology-enabled discovery of genetically diverse hepaciviruses in a new host. J. Virol. 2012, 86, 6171-6178. [CrossRef]

3. Li, L.; Diab, S.; McGraw, S.; Barr, B.; Traslavina, R.; Higgins, R.; Talbot, T.; Blanchard, P.; Rimoldi, G.; Fahsbender, E.; et al. Divergent astrovirus associated with neurologic disease in cattle. Emerg. Infect. Dis. 2013, 19, 1385-1392. [CrossRef]

4. Pfaff, F.; Schlottau, K.; Scholes, S.; Courtenay, A.; Hoffmann, B.; Höper, D.; Beer, M. A novel astrovirus associated with encephalitis and ganglionitis in domestic sheep. Transbound. Emerg. Dis. 2017, 64, 677-682. [CrossRef]

5. Asplin, F.D. Duck Hepatitis. Vet. Rec. 1965, 77, 487-488.

6. Gough, R.; Collins, M.; Borland, E.; Keymer, L. Astrovirus-like particles associated with hepatitis in ducklings. Vet. Rec. 1984, 114, 279. [CrossRef]

7. Yamaguchi, S.; Imada, T.; Kawamura, H. Characterization of a picornavirus isolated from broiler chicks. Avian Dis. 1979, 23, 571-581. [CrossRef]

8. Imada, T.; Taniguchi, T.; Yamaguchi, S.; Minetoma, T.; Maeda, M.; Kawamura, H. Susceptibility of Chickens to Avian Nephritis Virus at Various Inoculation Routes and Ages. Avian Dis. 1981, 25, 294-302. [CrossRef]

9. Connor, T.J.; McNeilly, F.; McFerran, J.B.; McNulty, M.S. A survey of avian sera from Northern Ireland for antibody to avian nephritis virus. Avian Pathol. 1987, 16, 15-20. [CrossRef]

10. Frazier, J.A.; Howes, K.; Reece, R.L.; Kidd, A.W.; Cavanagh, D. Isolation of non-cytopathic viruses implicated in the aetiology of nephritis and baby chick nephropathy and serologically related to avian nephritis virus. Avian Pathol. 1990, 19, 139-160. [CrossRef]

11. Shirai, J.; Tanimura, N.; Uramoto, K.; Narita, M.; Nakamura, K.; Kawamura, H. Pathologically and serologically different avian nephritis virus isolates implicated in etiology of baby chick nephropathy. Avian Dis. 1992, 36, 369-377. [CrossRef]

12. Mandoki, M.; Dobos-Kovacs, M.; Bakonyi, T.; Rusvai, M. Molecular diagnosis of avian nephritis: Preliminary report. Acta Vet. Hung. 2006, 54, 51-60. [CrossRef]

13. Hewson, K.A.; O’Rourke, D.; Noormohammadi, A.H. Detection of avian nephritis virus in Australian chicken flocks. Avian Dis. 2010, 54, 990-993. [CrossRef]

14. Gogoi, S.M.; Gulhane, A.B.; Deshpande, A.A.; Balaguru, P. Isolation and Identification of Avian Nephritis Virus from Commercial Broiler Chickens. J. Anim. Res. 2017, 7, 299. [CrossRef]

15. Shirai, J.; Nakamura, K.; Narita, M.; Furuta, K.; Hihara, H.; Kawamura, H. Visceral urate deposits in chicks inoculated with avian nephritis virus. Vet. Rec. 1989, 124, 658. [CrossRef]

16. Narita, M.; Ohta, K.; Kawamura, H.; Shirai, J.; Nakamura, K.; Abe, F. Pathogenesis of renal dysfunction in chicks experimentally induced by avian nephritis virus. Avian Pathol. 1990, 19, 571-582. [CrossRef]

17. Narita, M.; Kawamura, H.; Nakamura, K.; Shirai, J.; Furuta, K.; Abe, F. An immunohistological study on the nephritis in chicks experimentally produced with avian nephritis virus. Avian Pathol. 1990, 19, 497-509. [CrossRef]

18. Mandoki, M.; Bakonyi, T.; Ivanics, E.; Nemes, C.; Dobos-Kovacs, M.; Rusvai, M. Phylogenetic diversity of avian nephritis virus in Hungarian chicken flocks. Avian Pathol. 2006, 35, 224-229. [CrossRef]

19. Imada, T.; Yamaguchi, S.; Mase, M.; Tsukamoto, K.; Kubo, M.; Morooka, A. Avian nephritis virus (ANV) as a new member of the family Astroviridae and construction of infectious ANV cDNA. J. Virol. 2000, 74, 8487-8493. [CrossRef]

20. Madeley, C.; Cosgrove, B. $28 \mathrm{~nm}$ particles in faeces in infantile gastroenteritis. Lancet 1975, 306, 451-452. [CrossRef]

21. Matsui, S.; Greenberg, H. Fields Virology. In Astroviruses; Knipe, D.M., Howley, P.M., Eds.; Lippincott-Raven Publishers: Philadelphia, PA, USA, 2001.

22. Takase, K.; Shinohara, K.; Tsuneyoshi, M.; Yamamoto, M.; Yamada, S. Isolation and characterisation of cytopathic avian enteroviruses from broiler chicks. Avian Pathol. 1989, 18, 631-642. [CrossRef]

23. Shirai, J.; Nakamura, K.; Shinohara, K.; Kawamura, H. Pathogenicity and antigenicity of avian nephritis isolates. Avian Dis. 1991, 35, 49-54. [CrossRef]

24. Willcocks, M.M.; Brown, T.D.; Madeley, C.R.; Carter, M.J. The complete sequence of a human astrovirus. J. Gen. Virol. 1994, 75, 1785-1788. [CrossRef]

25. Méndez, E.; Fernández-Luna, T.; López, S.; Méndez-Toss, M.; Arias, C.F. Proteolytic processing of a serotype 8 human astrovirus ORF2 polyprotein. J. Virol. 2002, 76, 7996-8002. [CrossRef]

26. Méndez, E.; Murillo, A.; Velázquez, R.; Burnham, A.; Arias, C.F. Replication Cycle of Astroviruses: Astrovirus Research; Springer: Berlin/Heidelberg, Germany, 2012; pp. 19-45. 
27. Jiang, B.; Monroe, S.S.; Koonin, E.V.; Stine, S.E.; Glass, R.I. RNA sequence of astrovirus: Distinctive genomic organization and a putative retrovirus-like ribosomal frameshifting signal that directs the viral replicase synthesis. Proc. Natl. Acad. Sci. USA 1993, 90, 10539-10543. [CrossRef]

28. Monroe, S.S.; Jiang, B.; Stine, S.E.; Koopmans, M.; Glass, R.I. Subgenomic RNA sequence of human astrovirus supports classification of Astroviridae as a new family of RNA viruses. J. Virol. 1993, 67, 3611-3614. [CrossRef]

29. Krishna, N.K. Identification of structural domains involved in astrovirus capsid biology. Viral Immunol. 2005, 18, 17-26. [CrossRef]

30. de Wit, J.J.; Ten Dam, G.B.; van de Laar, J.M.A.M.; Biermann, Y.; Verstegen, I.; Edens, F.; Schrier, C.C. Detection and characterization of a new astrovirus in chicken and turkeys with enteric and locomotion disorders. Avian Pathol. 2011, 40, 453-461. [CrossRef]

31. Todd, D.; Trudgett, J.; Smyth, V.J.; Donnelly, B.; McBride, N.; Welsh, M.D. Capsid protein sequence diversity of avian nephritis virus. Avian Pathol. 2011, 40, 249-259. [CrossRef]

32. Koci, M.D.; Schultz-Cherry, S. Avian astroviruses. Avian Pathol. 2002, 31, 213-227. [CrossRef]

33. De, A.; Sarkar, T.; Nandy, A. Bioinformatics studies of Influenza A hemagglutinin sequence data indicate recombination-like events leading to segment exchanges. BMC Res. Notes 2016, 9, 222. [CrossRef]

34. Simon-Loriere, E.; Holmes, E.C. Why do RNA viruses recombine? Nat. Rev. Microbiol. 2011, 9, 617-626. [CrossRef]

35. Wohlgemuth, N.; Honce, R.; Schultz-Cherry, S. Astrovirus evolution and emergence. Infect. Genet. Evol. J. Mol. Epidemiol. Evol. Genet. Infect. Dis. 2019, 69, 30-37. [CrossRef]

36. Pantin-Jackwood, M.J.; Spackman, E.; Woolcock, P.R. Molecular characterization and typing of chicken and turkey astroviruses circulating in the United States: Implications for diagnostics. Avian Dis. 2006, 50, 397-404. [CrossRef]

37. Walter, J.E.; Briggs, J.; Guerrero, M.L.; Matson, D.O.; Pickering, L.K.; Ruiz-Palacios, G.; Berke, T.; Mitchell, D.K. Molecular characterization of a novel recombinant strain of human astrovirus associated with gastroenteritis in children. Arch. Virol. 2001, 146, 2357-2367. [CrossRef]

38. Chamings, A.; Hewson, K.A.; O’Rourke, D.; Ignjatovic, J.; Noormohammadi, A.H. High-resolution melt curve analysis to confirm the presence of co-circulating isolates of avian nephritis virus in commercial chicken flocks. Avian Pathol. 2015, 44, 443-451. [CrossRef]

39. Espinoza, L.L.; Beserra, L.A.R.; Soares, R.M.; Gregori, F. Avian nephritis virus (ANV) on Brazilian chickens farms: Circulating genotypes and intra-genotypic diversity. Arch. Virol. 2016, 161, 3455-3462. [CrossRef]

40. Smart, I.; Barr, D.; Reece, R.; Forsyth, W.; Ewing, I. Experimental reproduction of the runting-stunting syndrome of broiler chickens. Avian Pathol. 1988, 17, 617-627. [CrossRef]

41. Shapiro, F.; Nir, I.; Heller, D. Stunting syndrome in broilers: Effect of stunting syndrome inoculum obtained from stunting syndrome affected broilers, on broilers, leghorns and turkey poults. Poult. Sci. 1998, 77, 230-236. [CrossRef]

42. McNulty, M.S.; Allan, G.M.; Connor, T.J.; McFerran, J.B.; McCracken, R.M. An entero-like virus associated with the runting syndrome in broiler chickens. Avian Pathol. 1984, 13, 429-439. [CrossRef]

43. Spackman, D.; Gough, R.E.; Collins, M.S.; Lanning, D. Isolation of an enterovirus-like agent from the meconium of dead-in-shell chicken embryos. Vet. Rec. 1984, 114, 216-218. [CrossRef] [PubMed]

44. Smyth, J.A.; Connor, T.J.; McNeilly, F.; Moffet, D.A.; Calvert, V.M.; McNulty, M.S. Studies on the pathogenicity of enterovirus-like viruses in chickens. Avian Pathol. 2007, 36, 119-126. [CrossRef] [PubMed]

45. Pantin-Jackwood, M.J.; Strother, K.O.; Mundt, E.; Zsak, L.; Day, J.M.; Spackman, E. Molecular characterization of avian astroviruses. Arch. Virol. 2011, 156, 235-244. [CrossRef] [PubMed]

46. Kang, K.I.; El-Gazzar, M.; Sellers, H.S.; Dorea, F.; Williams, S.M.; Kim, T.; Collett, S.; Mundt, E. Investigation into the aetiology of runting and stunting syndrome in chickens. Avian Pathol. 2012, 41, 41-50. [CrossRef]

47. Devaney, R.; Trudgett, J.; Trudgett, A.; Meharg, C.; Smyth, V. A metagenomic comparison of endemic viruses from broiler chickens with runting-stunting syndrome and from normal birds. Avian Pathol. 2016, 45, 616-629. [CrossRef]

48. Nuñez, L.F.N.; Parra, S.H.S.; Astolfi-Ferreira, C.S.; Carranza, C.; De La Torre, D.I.; Pedroso, A.C.; Ferreira, A.J.P. Detection of enteric viruses in pancreas and spleen of broilers with runting-stunting syndrome (RSS). Pesqui. Veterinária Brasileira 2016, 36, 595-599. [CrossRef]

49. Smyth, V.J. A Review of the Strain Diversity and Pathogenesis of Chicken Astrovirus. Viruses 2017, 9, 29. [CrossRef]

50. Takase, K.; Uchimura, T.; Yamamoto, M.; Yamada, S. Susceptibility of embryos and chicks, derived from immunized breeding hens, to avian nephritis virus. Avian Pathol. 1994, 23, 117-125. [CrossRef]

51. Ghodasara, P.; Prajapati, K.S.; Ghodasara, D.J.; Joshi, B.; Thakkar, H.; Banerjee, J.; Pal, J. Isolation and detection of avian nephritis virus by RT-PCR from commercial broiler flocks affected with visceral gout in India. Indian J. Vet. Pathol. 2015, 39, 54-57. [CrossRef]

52. Nunez, L.F.N.; Parra, S.H.S.; De la Torre, D.; Catroxo, M.H.; Buim, M.R.; Chacon, R.V.; Ferreira, C.S.A.; Piantino Ferreira, A.J. Isolation of avian nephritis virus from chickens showing enteric disorders. Poult. Sci. 2018, 97, 3478-3488. [CrossRef]

53. Biđin, M.; Biđin, Z.; Majnarić, D.; Tišljar, M.; Lojkić, I. Circulation and phylogenetic relationship of chicken and turkey-origin astroviruses detected in domestic ducks (Anas platyrhynchos domesticus). Avian Pathol. 2012, 41, 555-562. [CrossRef] [PubMed]

54. Reece, R.; Howes, K.; Frazier, J.A. Experimental factors affecting mortality following inoculation of chickens with avian nephritis virus (G-4260). Avian Dis. 1992, 36, 619-624. [CrossRef] [PubMed]

55. Zerbino, D.R.; Birney, E. Velvet: Algorithms for de novo short read assembly using de Bruijn graphs. Genome Res. 2008, 18, 821-829. [CrossRef] [PubMed] 
56. Zerbino, D.R. Using the Velvet de novo assembler for short-read sequencing technologies. Curr. Protoc. Bioinform. 2010, 31, 11-15. [CrossRef] [PubMed]

57. Geer, L.Y.; Marchler-Bauer, A.; Geer, R.C.; Han, L.; He, J.; He, S.; Liu, C.; Shi, W.; Bryant, S.H. The NCBI BioSystems database. Nucleic Acids Res. 2010, 38, D492-D496. [CrossRef] [PubMed]

58. Mitra, S.; Rupek, P.; Richter, D.C.; Urich, T.; Gilbert, J.A.; Meyer, F.; Wilke, A.; Huson, D.H. Functional analysis of metagenomes and metatranscriptomes using SEED and KEGG. BMC Bioinform. 2011, 12 (Suppl. S1), S21. [CrossRef]

59. Huson, D.H.; Beier, S.; Flade, I.; Gorska, A.; El-Hadidi, M.; Mitra, S.; Ruscheweyh, H.J.; Tappu, R. MEGAN Community Edition-Interactive Exploration and Analysis of Large-Scale Microbiome Sequencing Data. PLoS Comput. Biol. 2016, 12, e1004957. [CrossRef]

60. Meyer, F.; Paarmann, D.; D’Souza, M.; Olson, R.; Glass, E.; Kubal, M.; Paczian, T.; Rodriguez, A.; Stevens, R.; Wilke, A.; et al. The metagenomics RAST server-A public resource for the automatic phylogenetic and functional analysis of metagenomes. BMC Bioinform. 2008, 9, 386. [CrossRef]

61. Kumar, S.; Stecher, G.; Li, M.; Knyaz, C.; Tamura, K. MEGA X: Molecular Evolutionary Genetics Analysis across Computing Platforms. Mol. Biol. Evol. 2018, 35, 1547-1549. [CrossRef]

62. Letunic, I.; Bork, P. Interactive tree of life (iTOL) v3: An online tool for the display and annotation of phylogenetic and other trees. Nucleic Acids Res. 2016, 44, W242-W245. [CrossRef]

63. Quevillon, E.; Silventoinen, V.; Pillai, S.; Harte, N.; Mulder, N.; Apweiler, R.; Lopez, R. InterProScan: Protein domains identifier. Nucleic Acids Res. 2005, 33 (Suppl. S2), W116-W120. [CrossRef] [PubMed]

64. Martin, D.; Murrell, B.; Golden, M.; Khoosal, A.; Muhire, B. RDP4: Detection and analysis of recombination patterns in virus genomes. Virus Evol. 2015, 1, 1-5. [CrossRef] [PubMed]

65. Padidam, M.; Sawyer, S.; Fauquet, C.M. Possible emergence of new geminiviruses by frequent recombination. Virology 1999, 265, 218-225. [CrossRef] [PubMed]

66. Martin, D.; Posada, D.; Crandall, K.; Williamson, C. A modified bootscan algorithm for automated identification of recombinant sequences and recombination breakpoints. Aids Res. Hum. Retrovir. 2005, 21, 98-102. [CrossRef]

67. Smith, J.M. Analyzing the mosaic structure of genes. J. Mol. Evol. 1992, 34, 126-129. [CrossRef]

68. Gibbs, M.J.; Armstrong, J.S.; Gibbs, A.J. Sister-scanning: A Monte Carlo procedure for assessing signals in recombinant sequences. Bioinformatics 2000, 16, 573-582. [CrossRef]

69. Holmes, E.C.; Worobey, M.; Rambaut, A. Phylogenetic evidence for recombination in dengue virus. Mol. Biol. Evol. 1999, 16, 405-409. [CrossRef]

70. Weiller, G.F. Phylogenetic profiles: A graphical method for detecting genetic recombinations in homologous sequences. Mol. Biol. Evol. 1998, 15, 326-335. [CrossRef]

71. Martin, D.; Rybicki, E. RDP: Detection of recombination amongst aligned sequences. Bioinformatics 2000, 16, 562-563. [CrossRef]

72. Boni, M.F.; Posada, D.; Feldman, M.W. An exact nonparametric method for inferring mosaic structure in sequence triplets. Genetics 2007, 176, 1035-1047. [CrossRef]

73. Smyth, V.J.; Jewhurst, H.L.; Wilkinson, D.S.; Adair, B.M.; Gordon, A.W.; Todd, D. Development and evaluation of real-time TaqMan(R) RT-PCR assays for the detection of avian nephritis virus and chicken astrovirus in chickens. Avian Pathol. 2010, 39, 467-474. [CrossRef] [PubMed]

74. Buchfink, B.; Xie, C.; Huson, D.H. Fast and sensitive protein alignment using DIAMOND. Nat. Methods 2015, 12, 59-60. [CrossRef] [PubMed]

75. Krueger, F. Trim galore. A wrapper tool around Cutadapt and FastQC to consistently apply quality and adapter trimming to FastQ files. Genome Announc. 2018, 6. [CrossRef]

76. Ewels, P.; Magnusson, M.; Lundin, S.; Käller, M. MultiQC: Summarize analysis results for multiple tools and samples in a single report. Bioinformatics 2016, 32, 3047-3048. [CrossRef] [PubMed]

77. Li, H. Aligning sequence reads, clone sequences and assembly contigs with BWA-MEM. arXiv 2013, arXiv:1303.3997.

78. Afgan, E.; Sloggett, C.; Goonasekera, N.; Makunin, I.; Benson, D.; Crowe, M.; Gladman, S.; Kowsar, Y.; Pheasant, M.; Horst, R.; et al. Genomics Virtual Laboratory: A Practical Bioinformatics Workbench for the Cloud. PLoS ONE 2015, 10, e0140829. [CrossRef]

79. Connor, T.R.; Loman, N.J.; Thompson, S.; Smith, A.; Southgate, J.; Poplawski, R.; Bull, M.J.; Richardson, E.; Ismail, M.; ElwoodThompson, S. CLIMB (the Cloud Infrastructure for Microbial Bioinformatics): An online resource for the medical microbiology community. Microb. Genom. 2016, 2, e000086. [CrossRef]

80. Milne, I.; Stephen, G.; Bayer, M.; Cock, P.J.; Pritchard, L.; Cardle, L.; Shaw, P.D.; Marshall, D. Using Tablet for visual exploration of second-generation sequencing data. Brief. Bioinform. 2013, 14, 193-202. [CrossRef]

81. Icho, T.; Wickner, R.B. The double-stranded RNA genome of yeast virus L-A encodes its own putative RNA polymerase by fusing two open reading frames. J. Biol. Chem. 1989, 264, 6716-6723. [CrossRef]

82. Hatfield, D.L.; Levin, J.G.; Rein, A.; Oroszlan, S. Translational Suppression in Retroviral Gene Expression: Advances in Virus Research; Elsevier: Amsterdam, The Netherlands, 1992; pp. 193-239.

83. Koonin, E.V. The phylogeny of RNA-dependent RNA polymerases of positive-strand RNA viruses. J. Gen. Virol. 1991, 72 Pt 9 , 2197-2206. [CrossRef] 
84. Bosch, A.G.S.; Krishna, N.K.; Méndez, E.; Monroe, S.S.; Pantin-Jackwood, M.; Schultz-Cherry, S. Virus Taxonomy: Classification and Nomenclature of Viruses; Ninth Report of the International Committee on the Taxonomy of Viruses; Elsevier Academic Press: New York, NY, USA, 2011; pp. 953-959.

85. Jonassen, C.M.; Jonassen, T.T.; Sveen, T.M.; Grinde, B. Complete genomic sequences of astroviruses from sheep and turkey: Comparison with related viruses. Virus Res. 2003, 91, 195-201. [CrossRef]

86. Mendez, E.; Salas-Ocampo, M.P.; Munguia, M.E.; Arias, C.F. Protein products of the open reading frames encoding nonstructural proteins of human astrovirus serotype 8. J. Virol. 2003, 77, 11378-11384. [CrossRef] [PubMed]

87. Dingwall, C.; Laskey, R.A. Nuclear targeting sequences-A consensus? Trends Biochem. Sci. 1991, 16, 478-481. [CrossRef]

88. Robbins, J.; Dilwortht, S.M.; Laskey, R.A.; Dingwall, C. Two interdependent basic domains in nucleoplasmin nuclear targeting sequence: Identification of a class of bipartite nuclear targeting sequence. Cell 1991, 64, 615-623. [CrossRef]

89. Willcocks, M.M.; Boxall, A.S.; Carter, M.J. Processing and intracellular location of human astrovirusnon-structural proteins. J. Gen. Virol. 1999, 80, 2607-2611. [CrossRef]

90. Ramadevi, N.; Rodriguez, J.; Roy, P. A leucine zipper-like domain is essential for dimerization and encapsidation of bluetongue virus nucleocapsid protein VP4. J. Virol. 1998, 72, 2983-2990. [CrossRef]

91. Dinman, J.D. Mechanisms and implications of programmed translational frameshifting. Wiley Interdiscip. Rev. RNA 2012, 3, 661-673. [CrossRef]

92. Jonassen, C.M.; Jonassen, T.O.; Grinde, B. A common RNA motif in the 3' end of the genomes of astroviruses, avian infectious bronchitis virus and an equine rhinovirus. J. Gen. Virol. 1998, 79 Pt 4, 715-718. [CrossRef]

93. Kofstad, T.; Jonassen, C.M. Screening of Feral and Wood Pigeons for Viruses Harbouring a Conserved Mobile Viral Element: Characterization of Novel Astroviruses and Picornaviruses. PLoS ONE 2011, 6, e25964. [CrossRef]

94. Bartel, D.P. MicroRNAs: Genomics, biogenesis, mechanism, and function. Cell 2004, 116, 281-297. [CrossRef]

95. Tengs, T.; Jonassen, C.M. Distribution and Evolutionary History of the Mobile Genetic Element s2m in Coronaviruses. Diseases 2016, 4, 27. [CrossRef] [PubMed]

96. Todd, D.; Trudgett, J.; McNeilly, F.; McBride, N.; Donnelly, B.; Smyth, V.J.; Jewhurst, H.L.; Adair, B.M. Development and application of an RT-PCR test for detecting avian nephritis virus. Avian Pathol. 2010, 39, 207-213. [CrossRef] [PubMed]

97. Imada, T.; Yamaguchi, S.; Miura, N.; Kawamura, H. Antibody survey against avian nephritis virus among chickens in Japan. Natl. Inst. Anim. Health Q. 1980, 20, 79-80.

98. Domingo, E.; Holland, J.J. RNA virus mutations and fitness for survival. Annu. Rev. Microbiol. 1997, 51, 151-178. [CrossRef] [PubMed]

99. Simmonds, P.; Welch, J. Frequency and dynamics of recombination within different species of human enteroviruses. J. Virol. 2006, 80, 483-493. [CrossRef] 